\title{
The aid of "bedside ultrasonography" for the emergency surgeon: the experience of a single centre
}

\author{
Antonino Agrusa, Giorgio Romano, Giuseppe Frazzetta*, Giuseppe Amato, Daniela Chianetta, Silvia Di Giovanni, \\ Giuseppe De Vita, Giuseppe Di Buono, Vincenzo Sorce, Gaspare Gulotta \\ From 7th WINFOCUS Italian Congress on Ultrasound in Emergency, Anaesthesiology and Critical Care \\ Lodi, Italy. 26-29 March 2014
}

\section{Introduction}

Abdominal blunt traumas are about 8-10\% of all causes of death for trauma, with an incidence only slightly less than head trauma [1]; most of them are due to roads crashes. In polytraumatized patients, echographic examination with Focused Assessment with Sonography in Trauma is often the first approach that can give useful indications and informations for the therapeutic strategy [2].

\section{Aim}

We performed a retrospective study on the use of ultrasounds, according to FAST protocol, for evaluation and monitoring of polytraumatized patients, admitted to our institution with a blunt abdominal trauma [3]. Our aim is to evaluate efficacy and diagnostic improvement of "Bedside Ultrasonography" in surgeon's hands and to evaluate its capacity in driving therapeutic choices.

\section{Materials and methods}

We examined the period between January 2012 and December 2013, selecting 33 patients come to our attention, in the department of emergency surgery in Policlinico of Palermo with polytrauma or blunt abdominal trauma, classified on triage as Class I or II (emergency or urgency): 26 with road trauma injuries; 7 with other causes.

\section{Results}

Five patients (15\%) were excluded from the study because of neurosurgical and/or orthopedic complications, having

\footnotetext{
* Correspondence: giuseppe.frazzetta@libero.it Dipartimento di Chirurgia Generale e D'Urgenza e dei Trapianti D’Organo, Azienda Ospedaliera Universitaria Policlinico "Paolo Giaccone" Palermo, Via Liborio Giuffrè 2890100 Palermo, Sicilia, Italy
}

no abdominal injuries, documented by echography or CT. 16 of the remaining 28 patients $(48,5 \%)$ had instable hemodynamic conditions so they underwent to explorative laparotomy and splenectomy for spleen rupture (13 patients $-81 \%$ ) or major liver damage (3 patients $-19 \%$ ), documented by CT or FAST performed in emergency room. For 12 patients $(36,4 \%)$ with stable hemodynamic conditions when admitted, it was considered a conservative treatment, so, in the hours after, they underwent to "bedside ultrasonography" for: retroperitoneal hematoma (2 patients $-17 \%$ ), undergoing, when the lesion became stable, to CT-guided drainage. Respectively 3 patients (25\%) and 4 patients $(33,3 \%)$ had hepatic and renal minor injuries and underwent to non-operative management and echographic follow-up; 3 patients (25\%) were followed with echographic approach because of "heterogeneous sonographic appearance of splenic parenchyma" and subsequent delayed spleen rupture. These patients underwent to surgery after echographic demonstration of sudden increase of abdominal effusion and signs of hypovolemic shock.

\section{Conclusions}

Our experience confirms the usefulness of "bedside" ultrasound technique as indispensable tool in the skills of the emergency surgeon [4]. Speed, feasibility, easy repeatability several in time, lack of invasiveness avoid delays and reduce diagnostic errors, driving therapeutic choices of the surgeon, in agreement and sometimes in lieu of laboratory data [5].

\section{SpringerOpen ${ }^{\circ}$}

(C) 2014 Agrus et al; licensee Springer This is an Open Access article distributed under the terms of the Creative Commons Attribution License (http://creativecommons.org/licenses/by/2.0), which permits unrestricted use, distribution, and reproduction in any medium, provided the original work is properly cited. 


\section{References}

1. Diercks DB, Mehrotra A, Nazarian DJ, Promes SB, Decker WW, Fesmire FM: Clinical policy: critical issues in the evaluation of adult patients presenting to the emergency department with acute blunt abdominal trauma. American College of Emergency Physicians. Ann Emerg Med 2011, 57(4):387-404.

2. Melanson SW1, Heller M: The emerging role of bedside ultrasonography in trauma care. Emerg Med Clin North Am 1998, 16(1):165-89.

3. Rippey JC1, Royse AG: Ultrasound in trauma. Best Pract Res Clin Anaesthesiol 2009, 23(3):343-62.

4. Bobbia X1, Hansel N2, Muller L2, Claret PG2, Moreau A2, Genre Grandpierre R2, Chenaitia H3, Lefrant JY2, de La Coussaye JE2: Availability and practice of bedside ultrasonography in emergency rooms and prehospital setting: A French survey. Ann Fr Anesth Reanim 2014, 33(3) e29-33, Epub 2014 Jan 20.

5. Sofia S: Bedside US imaging in multiple trauma patients. Part 1: US findings and techniques. J Ultrasound 2013, 16(4):147-159, eCollection 2013.

doi:10.1186/2036-7902-6-S2-A3

Cite this article as: Agrusa et al:: The aid of "bedside ultrasonography" for the emergency surgeon: the experience of a single centre. Critical Ultrasound Journal 2014 6(Suppl 2):A3.

\section{Submit your manuscript to a SpringerOpen ${ }^{\mathcal{O}}$ journal and benefit from:}

- Convenient online submission

- Rigorous peer review

- Immediate publication on acceptance

- Open access: articles freely available online

- High visibility within the field

- Retaining the copyright to your article

Submit your next manuscript at $\gg$ springeropen.com 